\title{
COVID-19: что происходит в отрасли и что будет дальше?
}

В этом году мир столкнулся с новым вызовом - пандемией COVID-19. Стремительное распространение новой коронавирусной инфекции потребовало от правительств разных стран введения различных мер, направленных на его сдерживание. В России был введен режим самоизоляции; на рабочих местах продолжили работу только те, от кого зависит функционирование критически важных процессов и производств непрерывного цикла; у кого есть возможность, работают удаленно; некоторые компании и предприятия приостановили свою деятельность. Кроме того, пандемия привела к проблемам в цепочках поставок во всем мире. Распространение вируса началось с Китая, на некоторое время промышленность в этой стране резко снизила свою активность, а ведь китайские производства являются одними из ключевых звеньев многих цепочек поставок.

Своими оценками того, как эта ситуация уже повлияла на отечественную электронную и радиоэлектронную промышленность, прогнозами ее дальнейших последствий и мнением о том, что могло бы помочь справиться с этими последствиями быстрее, мы попросили поделиться представителей компаний отрасли из разных областей: разработки и производства электронных и микроэлектронных изделий, контрактной сборки, поставки технологий, оборудования, САПР.
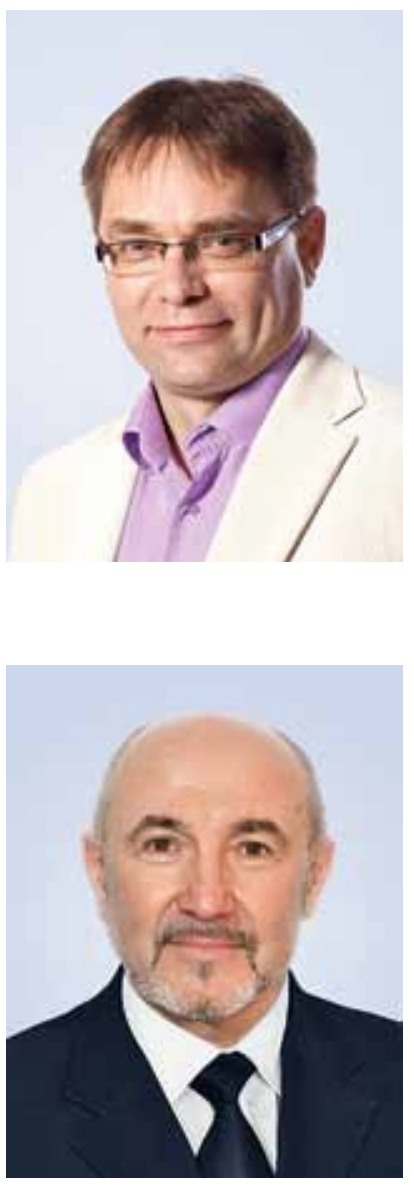

Алексей Новосёлов, директор по маркетингу АО «ПКК Миландр» Проиллюстрировать влияние пандемии COVID-19 на деятельность нашей компании можно очень просто: объем платежей и количество заявок на поставку продукции сейчас снизились в среднем на 30\% в сравнении с усредненными значениями за I квартал текущего года.

При этом наш производственный комплекс продолжает полноценную работу. Конструкторские

Игорь Корепанов, коммерческий директор АО «Ангстрем» Пандемия COVID-19 повлияла не столько на работу нашего предприятия, сколько на работу наших заказчиков и бизнес-партнеров. Мы - предприятие непрерывного цикла (особенно это относится к кристальному производству), поэтому мы не останавливали ни один технологический процесс. А вот работа по формированию производственных заданий от ство запросов на новые отгрузки. отделы, отдел кадров, бухгалтерия работают в удаленном режиме; склад, отдел продаж и маркетинга - в смешанном.

Думаю, данная ситуация не приведет к последствиям в отношении заказов и платежей в области ОПК, однако возможны проблемы с поставками комплектующих по кооперации. Справиться с последствиями влияния распространения COVID-19 в нашей отрасли, на мой взгляд, могли бы помочь увеличение авансирования по ГОз и опережающие закупки для нужд гособоронзаказа на 2021 год. две недели самоизоляции были сильно нарушены. За апрель 2020 года мы отгрузили заказчикам только лишь около 55-60\% от запланированного объема отгрузки продукции. И не из-за наших внутренних причин: заказчики не готовы были принимать готовую продукцию, и, конечно, снизилось количе-

Сильнее всего пострадал наш экспорт. Наш традиционный экспортный рынок-это Китай, Тайвань, Гонконг и ЮвА. Во-первых, у них долгое время 
действовали жесткие ограничения, и они не работали, а во-вторых, транспортная логистика практически остановилась. Поэтому и экспорт стоит почти без движения. Сейчас ситуация постепенно восстанавливается - и на внешнем, и на внутреннем рынке. Хотя за май месяц, видимо, не нормализуется. Но поскольку за первые три месяца текущего года у нас получился хороший задел (даже больше, чем мы ожидали) и по сбору заявок от заказчиков, и по нашей производственной программе, то за июньиюль мы это отставание компенсируем.

Сейчас наши производственные подразделения работают посменно и, понятное дело, в полной технологической одежде со всеми гигиеническими процедурами. Сами знаете, что в микроэлектронике спецодежда практически такая же, как у врачей в инфекционных больницах. Но мы, естественно, предприняли и много дополнительных усилий по дезинфекции и по противовирусной санитарии и гигиене. Практически все совещания проводим в форме онлайн-конференций. Всех сотрудников, которые не задействованы непосредственно в технологических операциях (особенно АУП и отделы развития проектов), перевели на удаленную работу. Также на удаленке и значительная часть разработчиков. Конечно, это создает большие неудобства, потому что завод - это многофакторная структура производства и управления, и любые мало-мальские сбои или задержки приводят к цепной реакции во многих процессах. Но пока мы «героически преодолеваем» и справляемся. А для меня, как для коммерческого директора, конечно, очень непривычно, что ни я, ни наш отдел продаж не может ездить в командировки на встречи кзаказчикам и партнерам. Никакие онлайн-возможности всё-таки не могут заменить роскошь прямого человеческого общения и очных обсуждений.

Я уверен, что последствия пандемии именно для нашей отрасли будут не столь большими. Просто сформируется отложенный спрос. А потом, во второй половине года, придется его удовлетворять в авральном порядке. С другой стороны, есть риск, что и наши потребности в материалах и комплектующих будут не полностью удовлетворены нашими поставщиками, потому что им тоже придется работать аврально. Словом, вторая половина года обещает быть очень напряженной. Дополнительно нынешняя пандемия вызвала заметное увеличение запросов от предприятий, проектирующих и производящих медицинскую аппаратуру. Такой вот драйвер импортозамещения для гражданских нужд случился, как бы цинично это не выглядело.

Что могло бы помочь быстрее справиться с последствиями? Вообще-то, это большой и многослойный вопрос. Если коротко, то поможет использование Фонда национального благосостояния для развития российской производственной базы (особенно высокотехнологичной), а не для прокладки всевозможных потоков для перекачки "национального достояния». Нам всем (я имею в виду российские микроэлектронные и радиоэлектронные предприятия) давно пора менять технологическое и измерительное оборудование. Но это в нынешнем мире для нашей отрасли выливается в такие огромные инвестиции, что ни одно предприятие не сможет себе этого позволить. Ну а в остальных нюансах мы сами себе поможем справиться...

\section{Равиль Дианов, генеральный директор ООО «АЛТ Мастер»}

Год 2019-й для нас, как контрактных сборщиков, и, возможно, для отрасли в целом прошел под знаком больших надежд. Не то чтобы он показал неожиданно большой рост (мы с нашей базы выросли на 15\%), но он открыл перспективу из-за появившегося фокуса внимания государства к таким проблемам отрасли, как неоднократно откладывавшиеся планы по развитию микроэлектроники, импортозамещение, витавшие в воздухе пожелания по развертыванию дополнительных мощностей, а также благодаря интересу зарубежных вендоров. Была некоторая проблема со слишком резкой попыткой внедрения не вполне обкатанных на практике решений, но сама попытка радовала. Два раза не обжегшись, ничего не сделаешь.
Отвечая на запросы рынка, мы провели активную инвестиционную работу, насколько позволяли возможности, по расширению и модернизации нашего производства: запустили пятую линию поверхностного монтажа, вторую линию штыревого монтажа пайкой двойной волной припоя по бессвинцовой технологии, линию селективной пайки и прочее помель-

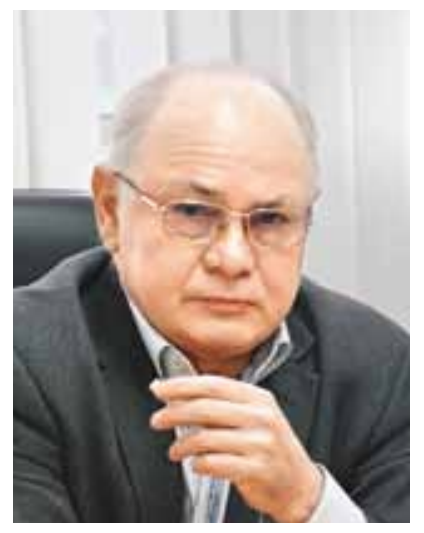
че. Приход нового состава правительства вселил робкую надежду на исправление традиционного графика сезонной загрузки: основной объем - с июля по август, остаток - ноябрь. 
Несколько насторожила ситуация с падением в феврале объемов от традиционных заказчиков на 10-30\%.

В марте ситуация с традиционными заказчиками начала выправляться, и тут, к концу месяца, COVID-19, резкое торможение и растерянность от непонимания происходящего. "Черный лебедь»? "Серый лебедь»? Как-нибудь само рассосется?

у нас есть опыт выживания в предыдущие кризисы 1998, 2008, 2014 годов. Но это означает: во-первых, снижение заработных плат (у нас нет внешних инвестиций); во-вторых, сокращение производственных площадей; в-третьих - на крайний случай - сокращение персонала.

В среднем по году у нас 250-300 активных заказчиков: от небольших инженерных компаний до крупных известных брендов. Среди них много востребованных именно в текущей ситуации (медицина, спецтехника, телеком, компьютерщики, жКX). Подводить людей и останавливать производство мы не можем себе позволить. Если не будет прямого приказа.

Разумеется, скупили все дезинфекторы в округе, ввели строгий режим прохода с контролем температуры и прочее необходимое. Тем не менее прогноз на май и далее пока не читается. COVID-19? Два месяца. Традиционный кризис? Два года. "Великая депрессия»? Ох, не знаю... Считаем разные сценарии.

В перечень "особо пострадавших" мы, да и отрасль в целом, не попадаем. Все преференции и послабления - не для нас. Мы-то постараемся и сами выжить. С соответствующими потерями .

Что помогло бы справиться? Много людей (например, АРПэ) думает об этом, предлагает решения. В общем виде от нас:

- не убивать текущие мизерные расходы на электронику. Понять проблему сезонной загрузки производств и что-то с ней делать;

- дополнительно ослабить нагрузку, связанную с налогами на труд (НДС, НДФЛ на совсем низкие заработные платы линейных исполнителей; ЕСН - спасибо, понизили);

- незабывать на всех уровнях очевидный ответ на вопрос: "Может ли страна жить и развиваться без электроники? Без искусственного интеллекта, ІоТ, ЦОДов, роботов, 5С, прочего, что движет миром? То есть без „мозгов“?”

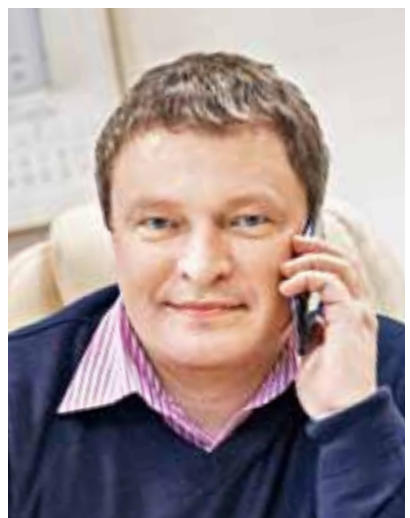

\section{Георгий Левин, генеральный директор ООО «МикроЭМ Технологии»}

Режим самоизоляции из-за COVID-19 больнее всего ударил по сегменту В2С. Там всё плачевно. «МикроЭМ Технологии» - компания в чистом виде из В2В, текущая ситуация характеризуется как сложная, но контролируемая. Держимся за счет высокой внутренней эффективности и понимания ситуации со стороны трудового коллектива.

К текущему кризису заранее подготовиться было невозможно. Дело не только в коронавирусной инфекции, хотя это самый болезненный из прилетевших «черных лебедей». Падение спроса обусловлено целым рядом факторов, некоторые из которых связаны с пандемией лишь косвенно. Это падение цен на нефть и последующий скачок курсов валют, нарушение налаженных логистических цепочек, закрытие базовых предприятий-поставщиков в Китае и Европе. Внутри страны предприятия-партнеры закрылись из-за объявленного режима самоизоляции их сотрудников. Мы встроены в различные цепочки и системы, такие как поставка импортных комплектующих, схемы финансирования, вместе с нашими заказчиками являемся частью производственных цепочек. И вот случился сбой, обрыв связей. Пришло время проверки на прочность своей бизнес-системы.

Наибольшее влияние на нашу работу оказали следующие факторы.

- В самом начале столкнулись с неразберихой в режиме работы контрагентов. Добрая половина заказчиков и такая же часть поставщиков приостановили свою работу. Многие предприятия отправили своих сотрудников в неоплачиваемые отпуска.

- Удлинились сроки поставки комплектующих, материалов, оснастки и т.п. Иногда более чем в два раза. Подстроили процессы, и сейчас последствия нивелированы.

- Пришлось искать замену закрывшимся предприятиям-поставщикам. На это ушло не менее трех недель в интенсивном режиме. Сегодня задача решена. С одним из новых поставщиков налаживаем дистрибуцию его продукции.

- Столкнулись с неплатежами. Это было самым болезненным, когда на протяжении длительного времени выпадали запланированные поступления и приходилось договариваться с поставщиками об отсрочках, согласовывать 
с заказчиками новые графики платежей. Сейчас экономика предприятия вновь приобрела управляемость.

- Пришлось перестраивать процессы и писать новые процедуры в цехах, уделив внимание защите персонала от возможного заражения закупили обеззараживатели, замеряем температуру у работников, постоянно проводим влажную уборку помещений с использованием спецсредств, все пользуются индивидуальными средствами защиты, разграничили пространство таким образом, чтобы между работниками было не менее 1,5 м, закрыли доступ посторонним на территорию.

- Часть персонала отправили на удаленную работу из дома. Это коммерческий, финансово-экономический блоки, инженеры, не связанные с работой оборудования. Производственный блок остался на рабочих местах исполнять контракты, по которым невозможно было получить отсрочку. Это изделия для медицины, в первую очередь приборы для обеззараживания помещений и кардиодиагностические комплексы, продукция для ОПК, для отечественного автопрома, связи и телекома.

- Пришлось сокращать часть расходов, оптимизировать и перестраивать закупочную деятельность. Ввели режим экономии расходных материалов.

- Наконец, пришлось разработать новый производственный календарь до отмены режима самоизоляции. Разделили персонал на две равнозначные группы и приступили кработе вахтовым методом, по две недели на вахту. Договорились с каждым персонально, что коллеги, не находящиеся на вахте, максимально ограничат контакты с внешним миром, проведут время дома. Обеспечив отсутствие контактов между бригадами, мы снизили риски закрытия предприятия на карантин в случае заболевания одного из членов бригады. Уже дважды происходила смена вахт, пока все идет по намеченному плану.

Принимаемые меры влекут дополнительные расходы и увеличение нагрузки на работающих. Однако эти мероприятия позволяют работать устойчиво в сложившейся ситуации, регулярно выплачивать заработную плату и в полной мере сохранить коллектив.

О коллективе я хочу сказать отдельно. Нет ни растерянности, ни уныния или страха. Я ощущаю поддержку и понимание со стороны каждого сотрудника, готовность работать в сложившихся условиях. Во многом благодаря этому мы смогли быстро мобилизоваться и выработать правильные шаги. Стараемся работать на опережение. Кстати, мы не только сохранили команду, но и ищем новых специалистов в нескольких новых сферах.

что касается дальнейшей судьбы компании, сейчас уже понятно, что из кризиса мы выйдем вполне достойно, окрепнув, приобретя неплохой опыт работы в нестандартных условиях. Заказчики в кризисное время стали лучше оценивать наши сильные стороны, меньше уходит времени на пустые разговоры, сделки заключаются быстрее.

Наряду с падением объема заказов наблюдаю процесс притока новых клиентов. За март-апрель заключено больше договоров, чем за весь IV квартал 2019 года.

Заказчикам мы продолжаем оказывать весь комплекс услуг, необходимый в производстве электроники: от разработки и редизайна, поставки компонентов и печатных плат, производства кабельной продукции до всех видов монтажа. Клиентам не надо искать разных исполнителей и объединять их усилия, контролируя каждого в отдельности. Всё происходит в режиме одного окна. Сейчас это преимущество вышло на одно из первых мест.

Имеющееся оборудование и технологии закрывают весь диапазон объемов заказов - от прототипов до крупной серии, и перестраиваются они в короткий срок.

Что касается последствий для нашей отрасли и экономики страны в целом, то явно будет сильное падение, восстановление экономики будет долгим. Предугадать масштабы отскока не возьмусь. Скажу лишь, что по окончании кризиса мы увидим новую реальность. Какие-то предприятия окрепнут, выйдут на новые рынки и прирастут новыми возможностями благодаря кризису. Какие-то предприятия исчезнут. Мы увидим примеры отраслевыхслияний и поглощений. Этот процесс еще не начался, он будет нарастать по мере обострения кризисных явлений. Предприятия, оказавшиеся финансово несостоятельными, перейдут в предбанкротное состояние, и их начнут приобретать госкорпорации и крупные частные компании, получившие помощь из бюджета.

Возрастает роль профессиональных отраслевых союзов и объединений. Вокруг них, как вокруг спасательного круга, будут объединяться компании отечественной электроники. Посмотрите, как сейчас активно работает Ассоциация разработчиков и производителей электроники (АРПЭ), членом которой мы являемся, а также 
вновь созданный Консорциум дизайн-центров и предприятий радиоэлектронной промышленности. Они формируют повестку, формулируют для правительства страны первоочередные меры поддержки

Мой прогноз о протяженности активной фазы кризиса достаточно пессимистичен. До июня-июля будут действовать разные ограничения. Тренд будет в сторону ослабления, но полноценно вернуться к прежнему распорядку сможем со второй половины лета. И это только при отсутствии второй и последующих волн эпидемии COVID-19.

Помимо негатива, проглядываются и положительные моменты. Государство снова обратило внимание на нашу отрасль. Первый вице-премьер проводит совещания и встречи, направленные на выработку мер помощи. И мне кажется, что данная ситуация сыграет нам всем на пользу. Посмотрим, появится ли такая помощь и кому она будет адресована.

Какие я вижу действенные способы для преодоления последствий пандемии:

1. Государственный протекционизм отрасли. Расписывать много не буду, есть достаточно информации в отраслевых изданиях. Назову лишь заградительные таможенные пошлины и гибкий подход к мерам нетарифного регулирования при импорте комплектующих. Сейчас тут сложилась система, в которой есть большой простор для оптимизации.

2. Включение отрасли в перечень пострадавших и последующее применение антикризисного налогового режима и других преференций для тех компаний, которые производят высокие добавленную стоимость и прибыль в выражении на одного работника. Пока вижу, что помощь идет не по адресу.

3. Для МСП было бы здорово, если хотя бы небольшая часть госзаказа пошла не в структуры Ростеха, а таким компаниям, как наша. Пока перспектива этого крайне пессимистична.

4. Продолжить работу по программе импортозамещения. Мы более трех лет оказываем такую услугу на рынке. Буксующие проекты должны стать драйвером роста компаний, аналогичных нашей. Могу назвать еще пятьшесть, готовых к этому не на словах.

Для того чтобы отрасль могла выйти из кризиса, а не утонула в "болоте» банкротств и неплатежей, необходимы стимулирование спроса со стороны государства и поддержка действительно эффективных компаний независимо от размера. Здесь должны быть понятные объективные критерии, а не формирование списков по принципу «этому дала, этому не дала". Тогда не будет бесконечного проедания бюджета и можно рассчитывать на реальный экономический подъем. Знаю, что многие участники рынка к этому готовы.

Желаю всем достойно выйти из этого испытания, остаться здоровыми, сохранить коллективы, и пусть этот кризис даст нам новые возможности для роста!

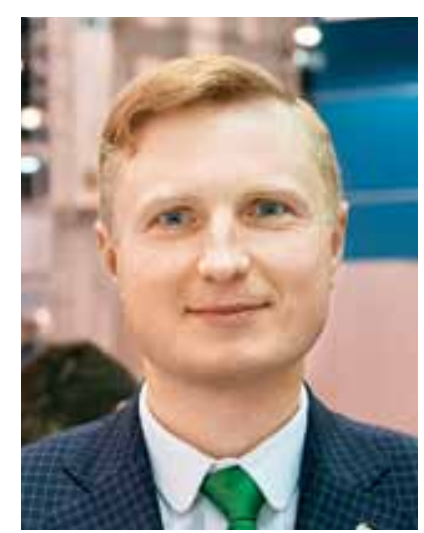

Антон Большаков, директор по Дорогая редакция журнала "ЭЛЕКТРОНИКА: Наука, Технология, Бизнес", вы обратились ко мне за экспертным мнением по вопросам, в которых я совершенно не являюсь экспертом. Насколько затяжными будут последствия пандемии для нашей компании и для отрасли? По-человечески хочется надеяться, что не затяжными и нечувствительными. Как укол прививки от коронавируса, которую, надеюсь, скоро создадут. А жизненный опыт подсказывает, что надо готовиться к худшему. Как эта ситуация повлияла на отрасль и на нас? Понятно, что ничего хорошего ни для какой компании в этом нет.

Дальше можно было бы пуститься в общие рассуждения о том, как минимизировать негативное

\section{маркетингу Группы компаний Остек}

влияние, соблюдая все требования и предписания самоизоляции

Давайте лучше поговорим о трендах, проявляющихся в явном или неявном виде в текущей ситуации. Восполняя недостаток общения в самоизоляции, я написал вопросы экспертам в разных сферах деятельности и из разных стран. Рад, что большинство откликнулось, в том числе и представитель вашей редакции. Мнение тех, кому доверяешь, важнее потока противоречивой информации от "экспертов", которые заполнили медиапространство. Среди результатов я бы выделил следующее:

- Цифровизация - уже не дань моде, а новая "нормальность»: условия вынудили перенести коммуникации и работу в цифровой мир. Те, у кого оцифрованы бизнес-и производственные процессы, у кого 
высокая степень автоматизации и роботизации производства, кто использует современные САПР и цифровые модели, математическое моделирование, получают преимущество уже сейчас и создают серьезный задел на будущее.

- Локализация и импортонезависимость. Встает вопрос, в какой степени цепочки поставок, охватывающие весь земной шар, являются хорошим выбором? Имеет ли смысл, чтобы целые отрасли промышленности зависели от производства на другом конце света? Не должны ли мы серьезнее сосредоточить наше внимание на том, что доступно «прямо за углом», в нашей стране? Но сама по себе эта идея не отрицает глобализацию, скорее это глокализация - обновленный проект глобализации с поддержкой местных различий, выгодных для продвижения товаров, технологий, идей.

- Медицина и life science получат дополнительный стимул к развитию. В большинстве стран кризис вскрыл целый ряд проблем в области здравоохранения, и это не только нехватка квалифицированного персонала, но и недостаточная техническая оснащенность медучреждений. Разработка новой медицинской техники и экосистем, систем персональной телемедицины с задействованием передовых технологий производства электроники получит новый импульс.

- Переосмысление качеств и навыков современного иидера. Как управлять людьми и процессами удаленно? В условиях не просто быстрых, а внезапных изменений. Как не только ставить задачи и контролировать результат, а создавать позитивный настрой и уверенность распределенной команды? Как принимать управленческие решения, от которых зависит, будет ли у бизнеса возможность выстоять в столь экстремальных обстоятельствах и при этом в условиях полной неопределенности? Как развить в себе навыки эмпатии, поддержки и внимания к сотрудникам?

- Сообщество. Коронакризис еще раз напомнил, что человек - социальное существо, а забота об окружающих - очень важная часть нашей жизни. Как заботиться о семье, когда изо дня в день вы вместе, и как заботиться о коллегах на расстоянии? Как не нанести вред совершенно незнакомым людям в общественных местах? Компании, ранее конкурировавшие, начинают объединяться перед лицом общих проблем. Сильное впечатление производят волонтерские акции помощи людям, которые в сложившейся ситуации действительно нуждаются в этой помощи. Это дает надежду на сплоченность общества.

В заключение отмечу, что, если и есть что-то хорошее в текущих обстоятельствах, то это то, что стало меньше суеты и больше возможности для осмысленных и результативных действий. Надеюсь, мои наблюдения дадут пищу для размышления о жизни в посткоронавирусную эпоху.

\section{Евгений Матов, генеральный директор ООО «АссемРус»}

Ситуация с распространением инфекции COVID-19 оказала существенное влияние на деятельность нашей компании: из-за введенных ограничений на передвижения, а также карантинных мер в отношении приезжающих из Москвы и Московской области в другие регионы России произошла практически полная остановка работ по монтажу, техническому обслуживанию оборудования и обучению клиентов. Также из-за частичной остановки многих производств в РФ и неопределенности со сроками разрешения данной ситуации и экономическими последствиями многие клиенты отложили реализацию всех проектов по оснащению производств. Пока говорить об экономическом эффекте в цифрах рано, но спад может быть значительным - оценочно, от 30 до 50\%.
В условиях самоизоляции мы не остановили свою деятельность, но перешли на удаленный режим работы везде, где это возможно. Часть операций в компании уже была на аутсорсинге или выполнялась удаленно, поэтому с этим проблем не возникло. Продолжаем общаться с клиентами, выставлять счета, коммерческие предложения, делаем презентации и даже демонстра-

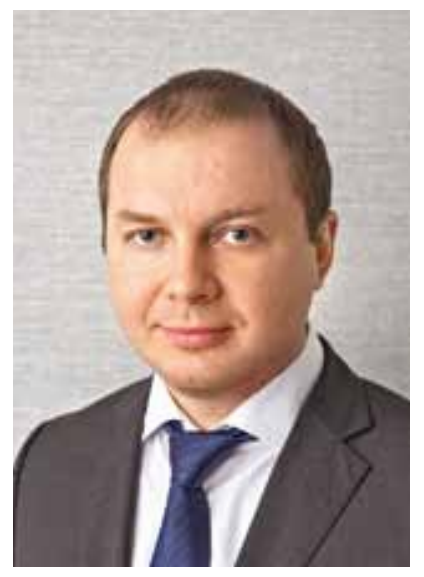
ции оборудования онлайн. Также продолжаем поставлять ранее заказанное оборудование и запчасти, хотя и с небольшими задержками. Естественно, начали активно 
сокращать расходы, от которых можем отказаться в текущей ситуации.

В данный момент оценить последствия этой ситуации непросто. Всё будет зависеть от длительности введенных ограничений и общей экономической ситуации, связанной не только с COVID-19, но и текущими курсами валют, и общим состоянием экономики. Если мы приступим к полноценной работе в ближайший месяц, то с большой долей вероятности сможем вернуться к обычным экономическим показателям деятельности в течение года. В любом случае и мы, и вся отрасль в целом столкнемся со значительным спадом в 2020 году. Один из первых проблемных сигналов - остановка платежей между всеми контрагентами.

Скорейшее снятие ограничений позволит оценить все последствия, проанализировать состояние компаний и составить план дальнейших действий отрасли. Даже такой шаг, хоть и не самый простой, добавит уверенности и успокоит ситуацию.

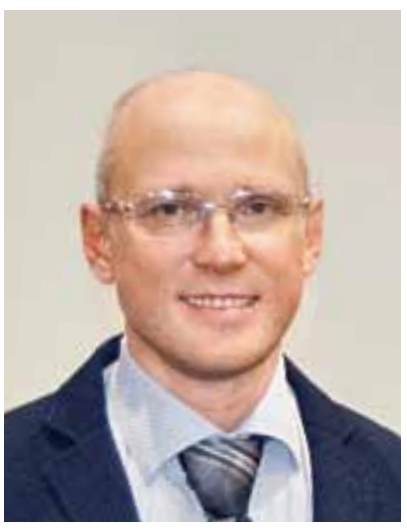

решла на удаленную работу

Для поддержки пользователей в их удаленной работе мы сразу же выпустили дополнительные домашние лицензии ПО. Дали промокод, обнуляющий стоимость профессиональных курсов и сертификации, чтобы дать инструмент повышения квалификации при вынужденном простое, где он есть.

Какими будут последствия пандемии для российской электронной отрасли? Запланированная Правительством РФ трансформация ускорится. убежден, что для микроэлектроники и приборостроения это реальное окно возможностей. Однако крайне обострятся требования к эффективности и срокам всего процесса разработки РЭА. В этом ключе проектирование будет полностью ориентировано на реальные, работающие, коммерчески и функционально состоятельные устройства и чипы. Мы, в своей нише, как раз в этой части и сильны. Смотрим с оптимизмом и желанием помочь. Еще я убежден, что откроются новые возможности по проектам, где российские и иностранные компании ранее не могли или не хотели искать общий язык.

Для того чтобы быстрее нивелировать экономические последствия пандемии, могла бы помочь локализация жестких мер, направленных на минимизацию распространения вируса, только в местах повышенной опасности заражения: аэропорты, вокзалы, больницы, школы, интернаты, воинские части... Конечно, я ждал бы большей опоры властей на сознательность наших граждан при одновременном активном снабжении их средствами защиты, дезинфекции и поддержки иммунитета. Неоценимую помощь оказывают цифровизация и автоматизация - там, где она внедрена и где ей умеют пользоваться.

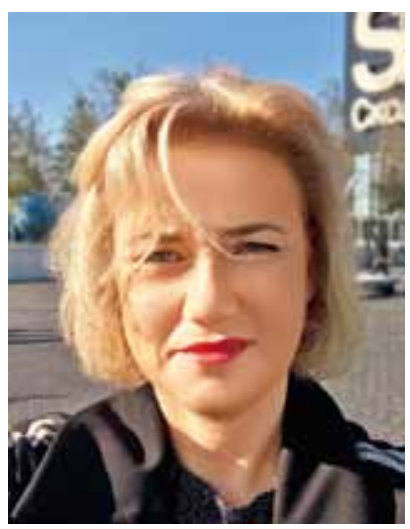

\section{Елена Иванова, генеральный директор 000 «Синопсис»}

В связи с возникшей из-за распространения коронавируса ситуацией компания Synopsys полностью перешла на удаленную работу. Только лаборатории, которые разрабатывают и тестируют наши аппаратные решения, замедлили или приостановили свою деятельность. Мы смогли настроить нашу работу с заказчиками здесь посредством приложения для конференц-связи, провели недавно первый вебинар. Мы адаптировались не сразу, но в течение двух недель приспособились к такой работе, наша инфраструктура была настроена на бо́льшую нагрузку. Лично мне тяжело без личных встреч и обсуждений как со своими коллегами, так и с заказчиками. Но ситуация требует. Устраиваем видеокофе-брейки, общаемся по телефону.

Перестроились и наши заказчики. С точки зрения бизнеса - конечно, все процессы замедлились, что-то перенеслось на некоторое время. 
Трудно сказать, насколько повлияет ситуация на бизнес за год; сейчас для нашей отрасли еще рано делать какие-либо выводы. У наших заказчиков никто проекты не отменял и, более того, сроки выполнения не двигал. Ближе к осени будет понятно, как это всё скажется.

Главное, чтобы не было второй волны и второго срока самоизоляции. Надо понимать, насколько наша экономика потребует поддержки и будет ли государство перераспределять ресурсы, направленные на развитие радиоэлектронной отрасли, на поддержку более пострадавших отраслей или будет использовать резервные фонды. Что касается ситуации с этим рынком в мире, последствия могут прослеживаться до нескольких лет.

Быстрее со всем этим справиться помогло бы чувство меры. Чувство меры во всем: в понимании ситуации и ответственности за себя и дорогих и близких людей, во введении ограничений и запретов, которые вследствие отсутствия этого понимания превращаются в драконовские меры, такие как введение пропусков и штрафов за нарушение. Надо все-таки начинать учиться на чужом опыте, а мы всё надеялись, что пронесет. Если бы мы были подготовлены к мерам защиты и правилам дистанцирования, когда всё это началось в Китае или хотя бы в Европе, то не нужно было бы выключать страну на полтора, а то и больше, месяца за счет работодателей. С другой стороны, эта ситуация обнажила все слабые места, показала, без чего можно обойтись и, наоборот, что для каждого является приоритетом.

Здоровья вам и мудрости!

Материал подготовлен Ю. С. Ковалевским

\section{НОВЫЕ КНИГИ ИЗДАТЕЛЬСТВА "ТЕХНОСФЕРА»}

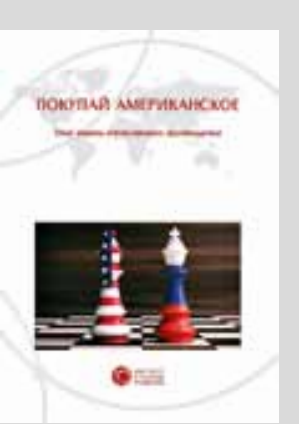

Цена 636 руб.

\section{ПОКУПАЙ АМЕРИКАНСКОЕ} Бочкарев О. И., Бошно С. В., Верник П. А. Под общей ред. О.И. Бочкарева

Книга посвящена исследованию комплекса нормативных правовых актов "Покупай американское" от исторического закона 1933 года до последних указов Президента США 2019 года. Авторы книги объясняют особенности американского протекционизма, демонстрируют механизмы защиты внутреннего рынка, рассматривают предпосылки таких правовых решений, приводят конкретные факты применения законодательства.

Практический опыт защиты отечественного товара и производителя очень актуален, так как в России сегодня активно формируются правовые положения об отечественном производителе и экономические меры его поддержки. Соответственно, лозунг "Делай/покупай российское" приобретает не только сугубо патриотическое, но и экономическое обоснование в русле современных тенденций мировой экономики.

\section{КАК ЗАКАЗАТЬ НАШИ КНИГИ?}

$凶$ 125319, Москва, а/я 91; ‘+7 495 234-0110; \$ +7 495 956-3346; knigi@technosphera.ru, sales@technosphera.ru 